\title{
How Far Should the State Go to Counter Prejudice?
}

\author{
A Positive State Obligation to Counter Dehumanisation
}

loanna Tourkochoriti*

\begin{abstract}
This article argues that it is legitimate for the state to practice soft paternalism towards changing hearts and minds in order to prevent behaviour that is discriminatory. Liberals accept that it is not legitimate for the state to intervene in order to change how people think because ideas and beliefs are wrong in themselves. It is legitimate for the state to intervene with the actions of a person only when there is a risk of harm to others and when there is a threat to social coexistence. Preventive action of the state is legitimate if we consider the immaterial and material harm that discrimination causes. It causes harm to the social standing of the person, psychological harm, economic and existential harm. All these harms threaten peaceful social coexistence. This article traces a theory of permissible government action. Research in the areas of behavioural psychology, neuroscience and social psychology indicates that it is possible to bring about a change in hearts and minds. Encouraging a person to adopt the perspective of the person who has experienced discrimination can lead to empathetic understanding. This, can lead a person to critically evaluate her prejudice. The paper argues that soft paternalism towards changing hearts and minds is legitimate in order to prevent harm to others. It attempts to legitimise state coercion in order to eliminate prejudice and broader social patterns of inequality and marginalisation. And it distinguishes between appropriate and non-appropriate avenues the state could pursue in order to eliminate prejudice. Policies towards eliminating prejudice should address the rational and the emotional faculties of a person. They should aim at using methods and techniques that focus on persuasion and reduce coercion. They should raise awareness of what prejudice is and how it works in order to facilitate well-informed voluntary decisions. The version of soft paternalism towards changing minds and attitudes defended in this article makes it consistent with liberalism.
\end{abstract}

Keywords: prejudice, soft paternalism, empathy, liberalism, employment discrimination, access to goods and services

\section{Introduction}

Is it legitimate for the state to change hearts and minds? Liberals accept that it is not legitimate for the state to intervene in in this area because ideas and beliefs are wrong in themselves. Changing how human beings think requires an additional justification to the extent that state paternalism is demeaning as it means treating citizens as immature human beings. There is always a danger of sliding into illiberalism. Only when there is a risk of harm to others and when there is a threat to social coexistence is it legitimate for the state to do so. For instance, anti-discrimination law aims to tackle stereotypes and prejudice, ways of thinking that materialise in acts that have discriminatory effects upon some persons who are classified as members of some groups. ${ }^{1}$ Stereotypical and prejudicial thinking is wrong and causes harm because it projects characteristics upon a person and dictates attitudes towards a person that deprive him/her of advantages. ${ }^{2}$ Harm is in these cases both material and immaterial. The evaluation of a stereotype or a prejudice relates to the social meaning of acts. ${ }^{3}$ It focuses on the wider social, cultural and historical contexts that discriminatory acts accentuate. ${ }^{4}$ Anti-discrimination law aims to tackle a social environment that is demeaning.

This article traces a theory of permissible government action. It argues that soft paternalism towards changing hearts and minds is legitimate in order to prevent harm to others. It attempts to legitimise state coercion in order to eliminate prejudice and broader social patterns

1. The tension for liberalism inherent in enforcing anti-discrimination law is analysed with great accuracy by John Gardner in 'Liberals and Unlawful Discrimination', 9 Oxford Journal of Legal Studies 11 (1989).

2. On prejudice as projection of qualities that deprive a person of the opportunity to define her personality and show it to others, see I. Tourkochoriti, "“Should Hate Speech be Protected?" Group Defamation, Party Bans, Holocaust Denial and the Divide Between (France) EuropeU.S.A.', 45(2) Columbia Human Rights Law Review 552-622 (2014).

3. On focusing on the social meaning of an act as expressing moral inferiority in order to define when discrimination is wrong, see A. Sangiovanni, Humanity without Dignity (2017), at 122.

4. See D. Hellman, When is Discrimination Wrong? (2008), at 35. 
of inequality and marginalisation in narrowly limited circumstances. And it distinguishes between appropriate and non-appropriate avenues the state could pursue in order to eliminate prejudice. Policies towards eliminating prejudice should address the rational and the emotional faculties of a person. They should aim at using methods and techniques that focus on persuasion and reduce coercion. They should raise awareness of what prejudice is and how it works in order to facilitate wellinformed voluntary decisions. The version of soft paternalism towards changing minds and attitudes defended in this article makes it consistent with liberalism. Changing 'hearts and minds' means, for the purposes of this article, changing ways of feeling, of thinking and of evaluating knowledge. The perspective adopted presupposes that cognition is affected both by emotion and reason. Research in the area of behavioural psychology, neuroscience and social psychology indicates that both reason and emotion are at play in human cognition. It also indicates that it is possible to bring about a change in hearts and minds. Encouraging a person to adopt the perspective of the person who experiences discrimination can lead to sympathetic understanding of her situation. Activating sympathetic understanding can lead a person to critically evaluate her prejudice. This evaluation can help her better apply the criterion of universalisability in her reflection on what rights persons should have.

This article aims to make a contribution to the literature on anti-discrimination law by providing an interdisciplinary approach and a multilevel analysis of discriminatory prejudice. It aims to make normative proposals by using conclusions of research in empirical science on what prejudice is and how it leads to discrimination. In this respect it uses data existing in recent research in the areas of behavioural psychology, neuroscience and social psychology. This study is divided into four parts. Part one offers an analysis of the types of harm that discrimination causes. In this respect, it analyses what prejudice is and how it works. Part two deals with whether it is possible to change hearts and minds. It presents research from the areas of behavioural psychology, social psychology and neuroscience to make the case that it is possible. Part three discusses whether it is legitimate for the state to change hearts and minds. In this respect it engages with Kant, Mill, Locke and Rawls. Part four discusses legal tools that exist and others that have been proposed. These legal tools can create a consciousness that discrimination is wrong and can, in the long term, lead to changing hearts and minds.

\section{What is the Harm Caused by Discrimination?}

For liberals to be able to defend government intervention in changing hearts and minds, it is compelling to increase consciousness about the harm that a person experiences. This harm can be defined in multiple ways. First, there is a harm to the social standing of the person. Discrimination perpetuates and accentuates a social context of oppression and marginalisation. Further, the harm to social standing leads to experiencing psychological harm. A person is made to feel inferior. Thirdly, there is material harm. Discrimination affects the distribution of rights and goods that a person gets. She may be denied access to professional opportunity or a good that she needs. Finally, there is an existential harm to the extent that discrimination affects the opportunities that a person has to improve her situation. In what follows I analyse each of these types of harm.

In order to be able to evaluate the harm that discrimination causes, it is important to analyse how prejudice works. Prejudice, praejudicium, can be a preliminary rational judgment, as Gadamer has noted. ${ }^{5}$ It can also be due to a hasty emotional response. The Latin etymology of the term prae-judicium points towards the idea of a preliminary judgment. This preliminary judgment can be formed on the basis of various conscious and unconscious factors. Gordon Alport provided in his study on Prejudice, which is the work of reference in social psychology, a definition of prejudice as "thinking ill of others without sufficient warrant". ${ }^{6}$ Research has shown that discriminatory behaviour is not only motivational but also cognitive. ${ }^{7}$ Prejudice has a cognitive component, an emotional component and a behavioural component, which form parts of an integrated whole. ${ }^{8}$ Prejudice is associated with stereotyping, the creation of categories of projected expectations. These concern the human qualities and the behaviour of a person. Prejudice and stereotyping lead to discriminatory behaviour. This is relevant to both cases of direct or indirect discrimination. Human beings apply stereotypes related to ability or other characteristics unconsciously. Unconscious biases affect what decision-makers see and interpret and how they evaluate persons.

Gordon Allport noted that forming in-group and outgroup mentality is part of human existence. ${ }^{9}$ Familiarity provides a basis for our existence which is defined by our membership in various social groups. These are defined in reference to an out-group, or in other words a "common enemy". ${ }^{10}$ Research in the area of neuroscience shows that our brains form in-group and outgroup dichotomies with stunning speed. ${ }^{11}$ This leads to

5. In his 'Truth and Method', (J. Weinshemere \& D.G. Marshall trans., 2nd ed.), at 272 seq.

6. Gordon Allport, The Nature of Prejudice [1954] (1979) 6.

7. See L.H. Krieger, 'The Content of our Categories: A Cognitive Bias Approach to Discrimination and Equal Employment Opportunity', 47 Stanford Law Review 1161, at 1164 (1994-1995).

8. Ibid., at 1174.

9. Gordon Allport, above n. 6, at 29.

10. As Allport notes, citing the French Biologist Felix le Dantec, ibid, 41. Freud in his Civilization and its Discontents, argued that group formation is possible when a group redirects its natural aggressivity towards an outgroup.

11. R. Sapolsky, Behave, The Biology of Humans at Our Best and Worst (2017), at 388. 
rapid automatic biases. These biases are due to hormones in the brain that prompt trust, generosity and cooperation towards in-groups and worse behaviour towards out-groups. Numerous experiments, again in the area of neuroscience, have shown that the brain processes within milliseconds differential images based on cues about race or gender. ${ }^{12}$ These lead to numerous ingroup biases, such as higher levels of cooperation. People feel positive associations with others who share the most meaningless traits with them. By age three to four, children have already grouped people by race and gender, have negative views of others and perceive other-race faces as being angrier than same-race faces. ${ }^{13}$ This is because children naturalize those social dimensions that the ambient culture marks as especially salient. ${ }^{14}$ Thinking in terms of "race" is unthinkable in the absence of culture and polity which create systems of cultural beliefs and channel sets of expectations. ${ }^{15}$

Furthermore, social cognition theory has shown that human thinking involves categorising. Human cognition is based on forming categories. ${ }^{16}$ Categories help the human mind impose some order upon the disorder of the world. They also help make it predictable. Categorising means turning 'fuzzy' differences into clear-cut distinctions. ${ }^{17}$ Stereotyping is an extension of the functioning of human cognition. Human beings learn to create categories at a young age. This forms part of the evolution of one's cognitive capacities. Categorising is associated with creating an exemplary member onto whom are projected a number of qualities. Categorisation leads to social stereotyping. Problems emerge because there is some arbitrariness inherent in stereotyping that dictates behaviour that deprives some persons of opportunities. Stereotyping associates persons with characteristics that belong to a group she is arbitrarily classified in. Children and adults develop stereotypes and prejudices concerning groups that are uncorrelated with any observable traits or behaviours. ${ }^{18}$ Stereotyping leads to essentialist thinking, viewing out-groups as homogeneous and interchangeable. ${ }^{19}$ The individuals stereotyped are seen as monolithic and undifferentiated. These cognitions are

12. Ibid., at 389

13. I.A. Hirschfield, 'Natural Assumptions: Race, Essence and Taxonomies of Human Kinds', 65 Social Research 331-349 (1998), R.S. Bigler et al., 'Developmental Intergroup Theory: Explaining and Reducing Children's Social Stereotyping and Prejudice', 16 Current Directions in Psychological Science 162-166 (2007), A.S. Baron and M.R. Banaji, 'The Development of Implicit Attitudes: Evidence of Race Evaluations from Ages 6, 10, and Adulthood', 17 Psychological Science 53 (2006). See also F.E. Aboud, Children and Prejudice (1988), R.S. Bigler et al., 'Social Categorization and the Formation of Intergroup Attitudes in Children', 68 Child Development 530 (1997), cited by Sapolsky, above n. 11, at 391.

14. I.A. Hirschfield, 'Natural Assumptions: Race, Essence and Taxonomies of Human Kinds', above n. 13, at 335.

15. Ibid

16. Allport, above n. 6, at 20.

17. See Krieger, above n. 7, at 1189

18. R.S. Bigler et al., 'Developmental Intergroup Theory: Explaining and Reducing Children's Social Stereotyping and Prejudice', above n. 13, at 165.

19. Sapolsky, above n. 11, at 399 post hoc justifications for feelings and intuitions. ${ }^{20}$ Developmental Pshychologists argue that our cognitive architecture makes some cultural representations possible and precludes others. ${ }^{21}$ And this architecture resonates with regimes of power and authority. ${ }^{22}$

Stereotyping means associating a person with qualities that are not necessarily chosen by her. This deprives her of the opportunity to form her own persona and show it to others. It is a violation of the autonomy of a person. It is an attempt to her ability to define her personality for herself and to show it to others. Discriminatory behaviour deprives a person of job opportunities and access to goods and services for imagined qualities and characteristics, which do not necessarily correspond with what that person is. If prejudice operates in this way, then it is legitimate for the government to engage in efforts that modify these patterns of thinking. Unconscious prejudice manifests itself in cases of both direct discrimination and indirect discrimination.

In discriminatory employment decisions, characteristics are used as proxies for job-related traits. Stereotyping involves concrete expectations projected upon others on the basis of characteristics that they have. If prejudice has a cognitive component, an emotional component and a behavioural component that form parts of an integrated whole, ${ }^{23}$ it involves systematic biases in intergroup judgment that can flow directly from stereotypes that are unconscious. This is the case because group mentality leads to a biased evaluation of in-group and out-group members. Stereotyping serves as a heuristic in our mental representations. It affects the evaluation of the behaviour of a person and its projected behaviour. It leads to all sorts of causal attributions that preclude searching for other relevant information. It even leads to projecting behaviours consistent with the stereotype that did not actually occur. ${ }^{24}$ Social cognition theory has shown that decision-making comprises perception, interpretation, attribution, memory and judgment. These operations take place in a way that is internalised and becomes automatic. Intent to discriminate does not necessarily play a role.

Having analysed how prejudice operates, it is now important to explore the types of harm that discrimination causes. Discrimination expresses and consolidates social power. Foucault has made us conscious that power is omnipresent within societies. ${ }^{25} \mathrm{~A}$ constructive reading of Foucault points towards raising awareness about the complicated ways in which we exercise and receive power. In this respect, his thought is very valuable for anti-discrimination law towards conceptualising

20. J. Haidt, 'The Emotional Dog and Its Rational Tail: A Social Intuitionist Approach to Moral Judgment', 108 Psychological Review 814 (2001), J. Haidt, The Righteous Mind: Why Good People are Divided by Politics and Religion (2012).

21. I.A. Hirschfield, 'Natural Assumptions: Race, Essence and Taxonomies of Human Kinds', at 349

22. Ibid.

23. Krieger, above n. 7 , at 1174

24. Ibid., at 1208.

25. See for instance, M. Foucault, The History of Sexuality, Engl. transl. by Robert Hurley (1990), at 92-95 
the immaterial harm that discrimination causes. If discrimination is caused by social power dynamics that it in return perpetuates, then it is legitimate to use the law in order to eliminate social power dynamics. Social power is expressed by conscious and unconscious acts of discrimination. It leads to the formation of stereotypes, and it accentuates them. The harm that a person experiences when she is facing discrimination relates to experiencing negative consequences owing to a characteristic that is arbitrarily projected to her and does not allow her to show who she is to others.

Social power thus contributes to affecting the social standing of some persons owing to stereotyping. As analysed earlier, this perception in relation to the social standing is conscious and unconscious. Discrimination is demeaning in that a person is depicted as not being of equal moral worth to others. ${ }^{26}$ As Deborah Hellman has noted, discriminatory behaviour is an expressive act. ${ }^{27} \mathrm{~A}$ person is made to feel inferior. Discriminatory acts demean or debase others. To demean someone has a social and a power dimension. ${ }^{28}$ The omission takes place in a context of unequal social power. If we accept an understanding of human dignity according to which human beings are entitled to unconditional respect, discriminating means not showing this unconditional respect. An example of this behaviour is placing an additional burden upon women to prove their fitness for a job opportunity. Context is very important for the evaluation of the acts of respect and for the acts of absence of respect.

Discrimination causes psychological harm as it leads to the internationalisation of the projected stereotypes of a person. A person is made to feel inferior to others. Discrimination undermines what Andrea Sangiovanni calls 'the structural conditions for a flourishing life'. ${ }^{29}$ By that he means the social-relational dimensions of disadvantaging someone through discrimination. The social relational element is not merely an aggravating circumstance, Sangiovanni notes, but fundamentally affects the wrongfulness of the act of discrimination. If, as Hegel noted, the sense of self of a person is formed by recognition, ${ }^{30}$ then treating another person as inferior in this context undermines her ability to develop a sense of herself as a moral agent. The person internalises the feeling of disrespect and is prevented from forming her self-respect. In other words, the person is negated what Rawls calls the social basis of self-respect. ${ }^{31}$ Our selfrespect is formed in the web of relationships we have with others and by the recognition of others. This can have detrimental effects on the very sense of self of the person. Having a conception of the self for each person is an important condition of living a flourishing life. Sangiovanni offers an interesting conception of the self:

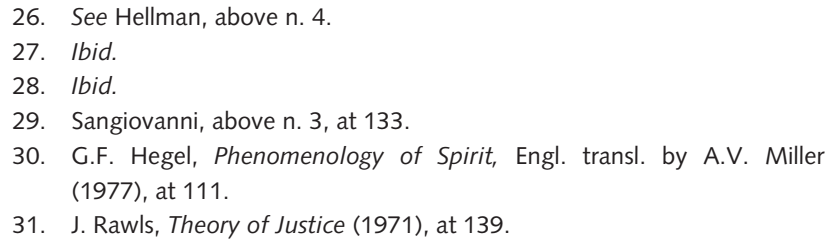

one that associates it with a person's values and normative commitments that are central to one's life. ${ }^{32}$

This harm is accentuated by the material harm that a person expresses when she is being discriminated against. A person refused a good or a service that she needs also has to make a greater effort in order to obtain that good or service. A person who is refused a cake to celebrate his or her same-sex marriage with another person needs to spend more time and energy in identifying a baker that is able to produce the cake that she needs. This material harm intensifies the psychological harm that the person experiences.

Discrimination causes another type of harm that can be described as existential. The existential harm that a person experiences relates to her facing additional obstacles in front of her when she is trying to transcend her circumstances and define her identity. Humanity is involved in an effort to transcend her circumstances in any attempt to make sense of the world. The search for meaning in life is a characteristic of every human being. This existential possibility in human life has been associated by some scholars with the idea of human dignity. ${ }^{33}$ In this effort to transcend their circumstances, some persons are facing more obstacles than others, which are the result of social constructs, prejudice and stereotypes. Discrimination on the basis of age, race, gender, sexual orientation, religion and disability creates additional obstacles to the persons that experience it, which should not be there. The persons who are experiencing discrimination on the basis of all these criteria are therefore entitled to additional protection. It is legitimate for the state to engage in action eliminating discrimination out of respect for human dignity. Respecting human dignity means treating human beings as having unconditional value. It means, to use Kant's famous phrase, treating human beings as ends and not as means. ${ }^{34}$ Persons who experience discrimination are denied the unconditional respect that should be recognised to them simply because they are human beings. This constitutes a deontological foundation for the right not to be discriminated against.

Harm is in these cases both material and immaterial. The evaluation of a stereotype or a prejudice relates to attributing social meaning and consequences to the acts of social actors. ${ }^{35}$ It focuses on the wider social, cultural and historical contexts in which their acts operate and possibly accentuate. ${ }^{36}$ Anti-discrimination law aims to tackle a social environment that is demeaning. To demean someone has a social and a power dimension. This operation of trying to bring about social change by changing collective states of mind implies challenges for liberalism to the extent that it implies evaluating social

32. Sangiovanni, above n. 3, at 79

33. See G. Kateb, Human Dignity, (2011) at 10.

34. I. Kant, Groundwork to the Metaphysics of Morals, Engl. transl. by James W. Ellington (1993), at 45

35. On focusing on the social meaning of an act as expressing moral inferiority in order to define when discrimination is wrong, see Sangiovanni, above n. 3, at 122 .

36. See Hellman, above n. 4. 
harm. Changing how human beings think requires an additional justification to the extent that state paternalism is itself demeaning as it means treating citizens as immature human beings. The danger of sliding into illiberalism is present in all these cases. The analysis in part 3 engages with these difficulties.

In all these cases of immaterial and material harm, discrimination perpetuates a social context of oppression and marginalisation that threatens peaceful coexistence. This necessitates taking action towards eliminating discrimination. If this is the harm that a person experiences when she is facing discrimination, it is legitimate for the state to try to eliminate prejudice. It is also legitimate for it to try to change the behaviour of those whose acts have an impact on others. Legislation against discrimination in the access to employment and goods and services aims to address these cases of injustice towards persons. It aims to eliminate a broader context of oppression and marginalisation that some persons have experienced. This broader context is actualised in every denial to them of a job opportunity or of basic goods and services that they need in order to survive. In these cases, there is concrete material harm to the persons who have experienced discrimination. There is also a form of immaterial harm that exists when within a society ideas circulate that are demeaning. Both these types of harm threaten social interaction and peaceful coexistence. Courts in many parts of the world may be reluctant to expand their understanding of harm in a way that includes all the types of harm just analysed. This means that it is preferable for the state to engage in soft paternalism that prevents them from occurring in the first place. Scholars have made suggestions, discussed in part 4, as to how courts should elaborate techniques that take prejudice into consideration in their application of anti-discrimination law. These suggestions concern the evaluation of the motivation in the application of anti-discrimination law and legal tools to confront systemic discrimination. The difficulties that courts have in taking them into consideration mean that it is preferable for the state to engage in preventive action. It is legitimate to attempt to modify at least how others manifest these beliefs through concrete acts. The hope always exists that, in the long term, by modifying their behaviour, persons carrying prejudices might be led to doubt also their beliefs and filter their prejudices.

\section{Is It Possible to Change Hearts and Minds?}

Before discussing whether, as a matter of principle, it is possible to make a case in favour of soft paternalism, it is worth reflecting whether it is possible to change hearts and minds. Research in the areas of behavioural psychology, neuroscience and social psychology indicates that it is possible to bring about a change in hearts and minds. Encouraging a person to adopt the perspective of the person of a minority group can lead to empathetic understanding of her situation. Activating empathetic understanding can lead a person to critically evaluate her prejudice. The use of arguments that address both the reason and the emotions of the person can help her realise some of the prejudices she is carrying. It can also help her eliminate them. This indicates that soft paternalism is justified on a consequentialist basis.

Gordon Allport noted that interpersonal contact between majority and minority groups can reduce prejudice. ${ }^{37}$ Allport noted the importance of institutional support and the importance of creating a perception of common interests and common humanity. Developmental psycholgists note that prejudice is under environmental control and might be shaped via educational, social and legal policies. ${ }^{38}$ Research in the area of behavioural psychology has also shown that intergroup prejudice can be reduced. ${ }^{39}$ Moral judgment is not a single act that occurs in a person's mind, but an ongoing process affected by reasons and arguments. ${ }^{40}$ Prejudice, intuition, reasoning and social influences interact to produce moral judgment. This means that creating a culture that fosters a more balanced, reflective and fairminded style of judgment can help people evaluate their intuitions and prejudices. ${ }^{41}$ Attitudes can change when individuals engage in active processing of brief messages. Interventions encouraging active consideration of counter-prejudicial thoughts can produce changes in attitudes towards out-groups. A thought process encouraging perspective taking, that is 'imagining the world from another's vantage point' has been shown to reduce prejudice. As analysed earlier, prejudice consists in categorising and in engaging in 'in-group' and 'outgroup' thinking. It was proved that encouraging individuals to actively take an out-group's perspective can durably reduce prejudice. During an experiment conducted in Florida, participants were encouraged to adopt 'analogic perspective-taking'. ${ }^{42}$ This involved encouraging participants to see how their own experience offered a perspective into minority groups' experiences, in this case transgender people. The experiment included short interaction with persons identifying as members of this group. It ended by asking voters to describe if and how the exercise had changed their minds. The intervention was described as being successful in increasing acceptance of transgender people. The experiment found that the change in attitudes was both lasting and politically relevant. The findings are highly

37. Gordon Allport, The Nature of Prejudice, 261. See also Anita Böcker, "Can Non-discrimination Law Change Hearts and Minds?, in this issue, 3.5 .

38. R.S. Bigler et al., 'Developmental Intergroup Theory: Explaining and Reducing Children's Social Stereotyping and Prejudice', 162.

39. D. Broockman and J. Kalla, 'Durably Reducing Transphobia: A Field Experiment on Door-to-Door Canvassing', 352 Science, Issue 6282220 (2016)

40. J. Haidt, 'The Emotional Dog and Its Rational Tail: A Social Intuitionist Approach to Moral Judgment', above n. 20, at 828-9.

41. Ibid, at 829.

42. D. Broockman and J. Kalla, 'Durably Reducing Transphobia: A Field Experiment on Door-to-Door Canvassing', above n. 39 at 221. 
significant as they seem incompatible with theories that depict prejudiced attitudes as durable and resistant to change.

As analysed earlier, research in the area of neuroscience shows that our brains form in-group and out-group dichotomies with stunning speed. ${ }^{43}$ But research in the same area has also shown that the roots of human morality are older than cultural institutions and constructs. ${ }^{44}$ Narratives related to protected values provoke a strong emotional reaction. ${ }^{45}$ Commitment to normative principles is associated with certain feelings caused by social emotions such as outrage and disgust. Emotional brain systems are involved in moral cognition. In general, interpreting stories in terms of protected principle-based values is associated with increased signal in the same brain regions activated by these kinds of moral judgments and social emotions. ${ }^{46}$ Furthermore, research has shown that the brain's systems for emotion appear to be engaged when protecting the aspects of our mental lives with which we strongly identify. ${ }^{47}$ These include our closely held beliefs, both political and religious. ${ }^{48}$ The same research shows that it is possible to change both religious and political beliefs. If emotions play such an important role in human thinking, then any attempt by the state to coerce in this area does not necessarily guarantee that change will follow. Only persuasive mechanisms are likely to be successful.

Other studies in the area of social psychology have shown that it is possible to eliminate group blame for acts committed by persons associated with them and thus to eliminate prejudice. A study conducted in the US related to anti-Muslim hostility following attacks by Muslims showed that by pointing out inconsistencies and hypocrisy, it is possible to change hearts and minds. ${ }^{49}$ Academics conducted an experiment by showing videos that exposed the unfairness of collective blame and challenged the perception of homogeneity about persons seen as members of social groups that have experienced discrimination. The experiment concerned Muslims in an attempt to eliminate prejudice in favour of extremist behaviour. When participants were shown films highlighting hypocrisy in blaming one religious group, e.g. Muslims for extremism, and no other

43. Sapolsky, above n. 11

44. Ibid., at 487, discussing the roots of justice in children and other primate animals

45. J.T. Kaplan, S.I. Gimbel, M. Dehghani, M.H. Immordino-Yang, K. Sagae, J.D. Wong, C.M. Tipper, H. Damasio, A.S. Gordon \& A. Damasio, 'Processing Narratives Concerning Protected Values: A CrossCultural Investigation of Neural Correlates', 27 Cerebral Cortex 1428-1438 (February 2017).

46. Ibid., at 1434 .

47. J.T. Kaplan, S.I. Gimbel \& S. Harris, 'Neural Correlates of Maintaining One's Political Beliefs in the Face of Counterevidence', Scientific Reports, 23 December 2016, www.nature.com/articles/srep39589.

48. S. Harris, J.T. Kaplan, A. Curiel, S.Y. Bookheimer, M. lacoboni, M.S. Cohen, 'The Neural Correlates of Religious and Nonreligious Belief', 4(10) PLOS ONE (2009)

49. E. Bruneau, N. Kteily \& E. Falk, 'Interventions Highlighting Hypocrisy Reduce Collective Blame of Muslims for Individual Acts of Violence and Assuage Anti-Muslim Hostility', Personality and Social Psychology Bulletin, http://pcnlab.asc.upenn.edu/wp-content/uploads/2017/10/ CB_R1_accepted_10-10-17.pdf (last visited 10 October 2017). religious groups, e.g. Christians for extremism, attitudes did change. Challenging the perception of Muslim homogeneity by providing counter-stereotypical examples can erode collective blame too. ${ }^{50}$ Watching a film where Muslims are allowed to speak for themselves allowed perspective taking, which is held to improve intergroup attitudes and foster prosocial behaviour. Another film provided social proof depicting examples of Americans espousing pro-Muslim behaviours; e.g. an interview with a man participating in demonstrations against Islam recounting the transformation he experienced after accepting an invitation from the imam of a mosque to observe a service. And two more films challenged common beliefs about Muslims, for instance that they hate America and that Muslim immigrants strain the economy by citing data countering these views. Some more films challenged the perception that Muslims are intrinsically supportive of violence. This would reduce the tendency to blame all Muslims for the violent actions of individual group members. Watching the films did change attitudes towards Muslims in all these cases. Longitudinal studies in the same area allowed testing temporal relationships with more confidence. ${ }^{51}$ These studies revealed that prejudice and social exclusion can be reduced with schooling interventions that affect intergroup structures.

These experiments seem to affirm Adam Smith's insightful description of the operation of sympathy in his Theory of Moral Sentiments. ${ }^{52}$ For Smith sympathy is a faculty of the mind that allows a human being to project herself through the use of her imagination into the situation of another human being. For Smith, it is the faculty of sympathy that allows morality. The experiments just described seem to provide empirical validation to Smith's moral theory. The faculty to sympathise seems to have been activated by them. This means that opinions and even prejudice can change through the proper activation of sympathetic understanding. Contemporary psychologists and neuroscientists use the term 'empathy' with the meaning that Smith attributed to sympathy. ${ }^{53}$ Empathy has a cognitive element. It means understanding the cause of someone's pain. It also means taking his perspective, 'walking in his shoes'. Research in neuroscience has shown that human beings are affected by emotional contagion. ${ }^{54}$ It has also shown that it can feel good to do good. ${ }^{55}$ But for a human being to actually engage in action he or she needs appropriate education towards helping others. This does not necessarily occur automatically. ${ }^{56}$ Behaviours do not become

50. Ibid., at 12

51. Anja Eller, Dominic Abrams and Miriam Koschate, "Can stateways change folkways? Longitudinal tests of the interactive effects of intergroup contact and categorization on prejudice", 72 Journal of Experimental Social Psychology, 21 (2017).

52. London [1853]

53. For psychologists, see P. Bloom, Against Empathy, The Case for Rational Compassion (2018). For neuroscientists, see Sapolsky, above n. 11 at 522 .

54. Sapolsky, above n. 11, at 524

55. Ibid., at 546

56. Ibid., at 552 
automatic unless a person is trained in them. The three experiments cited earlier in this part confirm this analysis. A person needs to be exposed to the situation of another who is carrying the characteristic associated with negative qualities. Exposure can lead to understanding someone else's situation.

If this is the case, then it is legitimate for the state to engage in action that activates sympathetic understanding in human beings. This can be done through seminars raising awareness about minority social groups. This is not the case of mobilisation of emotions that can lead to partiality feared by Kant. Scholars keep articulating the same concerns, warning against over-reliance on emotions in the formation of moral judgment. ${ }^{57}$ It is the kind of emotion mobilisation that can help a person reflect better on the application of Kant's universalisability rule. Understanding the situation of a person who experiences discrimination through emotional projection, i.e. a transgender person who wants to get married, can help a person improve her ability to perceive the conditions of the universalisability test. It can help her understand that a right to marriage should be recognised for everyone. Interpersonal communication that leads to emotional projection in someone else's situation can help a person better understand the conditions that can lead her reflection on what rights people should have. If in-group and out-group mentality leads to prejudice and discrimination, ${ }^{58}$ experiments like the ones analysed previously show that it is possible to expose a person to circumstances that can lead her to fair reasoning towards out-groups. Empathy can be stimulated in a way that, in coordination with reason, can lead to better judgments about correct moral reasoning about rights.

If it is legitimate for the state to eliminate social power dynamics that lead to discrimination, it is important to distinguish between appropriate and non-appropriate avenues the state could pursue in order to eliminate prejudice. Policies towards eliminating prejudice should address the rational and the emotional faculties of a person. They should aim at using methods and techniques that focus on persuasion and reduce coercion. They should aim at encouraging citizens to use their critical abilities. If discrimination occurs owing to unconscious patterns of thinking, it is very important to elaborate sophisticated tools to address them as well.

Scholarship on 'nudging' has highlighted the choice architecture that affects the decisions persons make. ${ }^{59}$ The term is crafted to mean the possibilities available to individuals in their decision-making in various areas that concern their life and their health. The factors that define this architecture are omnipresent even if people cannot see them. Numerous structures define our decisions. Nature, customs and traditions and spontaneous

57. For a re-articulation of these concerns by a psychologist, see Bloom, above n. 53.

58. Bloom, above n. 53, at 90, reaffirms this point

59. C. Sunstein, Why Nudge?, The Politics of Libertarian Paternalism (2014), at 14-15, A. Kemmerer, C. Möllers, M. Steinbeis \& G. Wagner (eds.), Choice Architecture in Democracies, Exploring the Legitimacy of Nudging (2016). and non-spontaneous orders. ${ }^{60}$ Adopting Foucault's perspective, we can say that all sorts of social power that are exercised upon us, consciously and unconsciously, provide a choice architecture. This includes private and public power. These visible and invisible structures that affect decision-making can be properly tuned by the state in order to eliminate prejudice that is conscious and unconscious. Creating this kind of architecture can be dictated on the basis of a soft paternalism towards eliminating prejudice before it materialises in action. In the area of discrimination where there is harm to others that is subtle and often immaterial, it is legitimate for the state to engage in preventive action towards changing hearts and minds. If prejudice is unconscious and often the result of social power that is invisible, then it is legitimate for the state to eliminate these social power dynamics. In other words, the state should opt towards the social structures that minimise the impact of prejudice that leads to discrimination. Governments, by highlighting some topics and downplaying others, can have a significant impact on the operation of prejudice. They can have an important role in mobilising sympathetic understanding that can help to eliminate prejudice. A society that wants to become well ordered cannot remain indifferent to social oppression. On the contrary, it should always be alert to discovering new ways according to which social power operates. Nudging should aim to raise awareness about how discrimination works in order to encourage persons to critically evaluate their prejudices.

The most compelling objection to nudging is the risk of manipulation. Manipulation consists in an attempt to reduce the use of the rational faculties of a person in order to lead them to a decision that benefits the manipulator to the detriment of the interests of the person who is manipulated. An effort to make every citizen realise that every person is worthy of equal unconditional respect can hardly be considered manipulating. An effort to persuade citizens that they should give a chance to every other fellow citizen to show to them who they are beyond any kind of prejudice can be seen as an effort to ensure informed choice in various areas of human action. Nudging with the aim of eliminating discrimination aims to encourage more discussion and participation in the political system. ${ }^{61}$ As Cass Sunstein notes, nudging exists de facto in all social contexts. Choice architecture exists by default. Governments always nudge. As Polanyi has famously written, 'the free market was planned, planning was not.' To paraphrase Polanyi, nudging always existed. It is important that the government practices nudging in a way that respects the dignity of all social members. In the case of discrimination where there is material and immaterial harm to
60. C.R. Sunstein, 'The Ethics of Choice Architecture', in A. Kemmerer, C Möllers, M. Steinbeis \& G. Wagner (eds.), Choice Architecture in Democracies, Exploring the Legitimacy of Nudging (2016) 21.

61. Cf. C. McCrudden and J. King, 'The Dark Side of Nudging: The Ethics, Political Economy, and Law of Libertarian Paternalism', in A. Kemmerer, C. Möllers, M. Steinbeis \& G. Wagner (eds.), Choice Architecture in Democracies, Exploring the Legitimacy of Nudging (2016) 113. 
others, nudging can only prevent awkward situations within civil society that threaten peaceful coexistence. It is thus compelling for the state to discover appropriate ways of 'nudging' towards reducing the risk of discriminatory behaviour. Nudges that point towards integrating harmoniously social members are democratic. They can be seen as ensuring equal respect that facilitates democratic participation for all members. And they can also be justified in reference to the concept of autonomy and dignity. They aim to ensure those principles for all. It is acceptable for the state to engage in action towards making citizens conscious of how discrimination operates. Increasing consciousness about what discrimination is and how it works can help citizens become more perceptive. It can encourage them to filter their prejudices in order to reduce the role of unconscious factors within decision-making. There are a number of measures that states can take. Civic education lessons offered during primary and secondary education are excellent methods towards changing hearts and minds early on. Classes teaching tolerance and equality for all are exercising a legitimate soft paternalism. Civic education can foster deliberative democracy and deliberative autonomy. ${ }^{62}$ In this respect, civic education can play a significant role in making students alert about how social power works, according to Foucault's perspective. Civic education should aim to encourage citizens that social power is omnipresent. We should be alert to the likelihood that we may be oppressing fellow citizens on the basis of the characteristic that they have. Civic education should encourage individual and social alertness towards raising awareness about potential sources of social power upon minority groups. They are the ideal laboratories of stimulating sympathetic understanding provided that they can allow free and uninhibited discussion of pressing social issues. Equal respect of all participants in every discussion is very important to eliminate prejudice through the use of argument. Civic education should teach tolerance and respect for difference, by allowing the respectful discussion of all opinions. Allowing students to express themselves in schools so that they feel that they are influencing "the climate and policies of their school' helps them develop into 'more effective, skilled, and knowledgeable citizens'. These lessons can also be combined with in-class and out-of-class experience, where students may engage in community service as well as 'academic study of the issues addressed by the students' service where students might discuss underlying causes of social problems'. ${ }^{63}$ These lessons should be obligatory despite objections raised in some context in reference to religious beliefs. ${ }^{64}$

62. See J.E. Fleming and L.C. McClain, Ordered Liberty: Rights, Responsibilities and Virtues (2013), at 118.

63. Peter Levine and Kei Kawashima-Ginsberg, 4.

64. In the city of Birmingham, in the UK, objections were raised to civics education teaching tolerance towards homosexuality by parents on the basis of their religious beliefs. The relevant protests led to court ruling in favour of exclusion zones; see 'LGBT Teaching Row: Birmingham Primary School Protests Permanently Banned', The Guardian, 26 November, www.bbc.co.uk/news/uk-england-birmingham-50557227.
When families neglect or do not provide civic education to their children, schools should step into this role. ${ }^{65}$ In fact, the bringing together of young people with different backgrounds itself ensures first-hand experience and interaction with various cultures that can operate towards eliminating prejudice.

Prefigurative politics can also be deployed in this direction. The state can provide the means to NGOs that are active in defending the rights of persons who have experienced discrimination to create short films and radio spots that can eliminate stereotypes. It can also mobilise public media to diffuse them. For instance, NGOs active in the area of protecting persons with disabilities would have valuable expertise to create short films indicating the special abilities these persons have. The state should subsidise them so that they engage in publicity efforts to raise awareness on these abilities. A short video clip describing the different abilities of a person considered 'disabled' can lead to an understanding of her situation and to changing stereotypes associated with 'disability'. This clip can be projected during advertising time by public broadcasting media. It can also be projected onto screens while queuing to receive public services, in public hospitals' waiting rooms, etc. A clip like this one can serve the role of well-intentioned 'nudging' of persons towards adopting the perspective of those considered 'disabled'.

Broad solutions that encourage collaborations across social groups can operate towards eliminating prejudice. The state needs to engage in wide policies of acculturation using various media to achieve its goals. It needs to encourage the citizens to transcend their perspective and to challenge their point of view. It needs to encourage them to adopt the perspective of those who have experienced discrimination and sympathise with them. As Martha Minow has noted, recognising that we are all different is what is needed to break the cycle of discrimination. ${ }^{66}$ Reflecting critically on the stereotypes and categories that our own thought needs is very important in this respect. Seminars informing about how prejudice works in the workplace and elsewhere are a type of measure that can help. It is legitimate for the state to require private employers to provide similar training to all employees related to how prejudice works in interpersonal decision-making processes.

The enforcement of antidiscrimination law can thus appear legitimate. Gordon Allport noted in one of the editions of his major work on Prejudice that most citizens would accept "a firmly enforced executive order" ..."as a fait accompli, with little protest or disorder. In part they do so because integrationist policies are usually in line with their own consciences (even though countering their prejudices)". ${ }^{67}$ There are some concerns in the enforcement of anti-discrimination law that relate to social cohesion. Enforcing anti-discrimination law can

65. Fleming and McClain, above n. 48, at 120-121.

66. M. Minow, 'Making All the Difference: Three Lessons in Equality, Neutrality, and Tolerance', 39 DePaul Law Review 1-13 (1989-1990).

67. Gordon Allport, Foreword to the 1958 edition of The Nature of Prejudice, above n. 6. 
lead to animosity between social groups that threatens peaceful coexistence. Scholars in the US have expressed this concern as the risk of 'balkanisation'. ${ }^{68}$ On the basis of this approach, anti-discrimination law should be enforced with caution in order not to lead to the breakup of social bonds. According to what are held to be neo-conservative arguments, anti-discrimination law should not be enforced because it perpetuates animosity between social groups. Justice Scalia, in his concurring opinion in Ricci v. DeStefano, articulated the idea that anti-discrimination law places 'a racial thumb on the scales... requiring employers to evaluate the racial outcomes of their policies and to make decisions based on those racial outcomes', a type of decision-making that is discriminatory. ${ }^{69}$ It is definitely preferable for the state to engage in nudging in order to prevent discrimination. Nevertheless, there are cases where besides nudging, anti-discrimination law should be enforced too when discrimination actually occurs. As empirical evidence has shown, the most effective means of changing behaviour in a population is to use a range of policy tools, regulatory and not. ${ }^{70}$

\section{Is It Legitimate for the State to Intervene in Changing Hearts and Minds?}

As analysed earlier, when discrimination results in concrete material harm, it is easier to make a case in favour of government intervention. In the area of thoughts and beliefs it is harder. Changing how human beings think requires an additional justification to the extent that state paternalism is itself demeaning as it means treating citizens as immature human beings. The risk of sliding into illiberalism is present. A good justification towards accepting government intervention is the risk of prejudice materialising in harm towards the individual. If prejudice is cognitive and thus unconscious, it is very important for the state to raise awareness in order to eliminate its negative unintended consequences. It is legitimate for the state to engage in action towards eliminating both aspects of prejudice, the rational and the emotional. If prejudice has both a rational and an irrational component, it is impossible to eliminate it by state coercion. Force cannot remove prejudice, 'make way for Truth, remove one Truth for another', Locke notes. ${ }^{71}$ Only methods that address both the rational and the emotional faculties, and possibly even 'nudging' (done

68. R. Siegel, 'From Colorblindness to Anti-Balkanization: An Emerging Ground of Decision in Race Equality Cases', 120 The Yale Law Journal 1278 (2011).

69. Ricci v. DeStefano, at 557 U.S. 557, at 594.

70. See House of Lords, Science and Technology Select Committee behaviour Change Report (2011) HR Paper 179, 5.13, cited in McCrudden and King, above n. 61, at 92

71. "Excerpts from a Third Letter for Toleration", in M. Goldie (ed.), A Letter concerning Toleration and Other Writings (2010) 78. properly and in a way that respects liberty) can contribute towards changing attitudes. Educational methods broadly conceived can contribute towards preventing behaviours and legal enforcement should intervene when it is necessary to restore harm.

Liberals agree that when harm to others is at stake, then it is legitimate for the state to intervene. Mill has articulated the harm principle that liberals hold as the canon for government intervention within civil society. ${ }^{72}$ According to this principle, the government may limit someone's liberty against his will only to prevent harm to others. ${ }^{73}$ A person's own good 'is not a sufficient warrant', Mill thinks, 'for which power can be exercised over him' ${ }^{74}$ People are amenable to society, he considers, only for conduct that concerns others. ${ }^{75}$ Mill makes a distinction between self-regarding and other-regarding acts. If we consider that our consciousness is social and defined in social interaction we realise that this distinction is artificial. Nevertheless, Mill still provides important insights into the meaning and purpose of the force that it is legitimate for the state to use. Only when concrete, material harm to others is caused, is it legitimate for the government to intervene. In the area of prejudice that leads to discriminatory behaviour, it is not legitimate for the state to intervene in order to change how citizens think because this is wrong in itself. It is only legitimate for the government to intervene in order to make sure that these thoughts do not materialise in actions that harm others.

Liberals underline the importance of the autonomy of the person. The state behaves paternalistically when it attempts to change the way a person thinks out of a concern for the well-being of that person. Kant has also noted that paternalism is 'the greatest conceivable despotism' because it treats human beings as immature beings and as unable to define happiness for themselves. ${ }^{76}$ It is possible to distinguish between 'hard' and 'soft' paternalism. ${ }^{77}$ According to Feinberg's definitions of the distinction, hard paternalists accept that it is necessary to protect competent adults against their will from the harmful consequences of their fully voluntary choices and undertakings. Soft paternalists accept that the state has the right to prevent self-regarding harmful conduct only when it is substantially involuntary or when temporary intervention is necessary to establish whether it is voluntary or not. ${ }^{78}$ The state's concern in this area is to help implement a person's 'real' choice. Soft paternalists generally argue that intervention is legitimate for generally competent people when factors that reduce voluntariness affect the decisions of a per-

72. Above n. 1

73. J. Stuart Mill, 'On Liberty', in J. Gray (ed.), On Liberty and Other Essays, (1998) at 14.

74. Ibid., at 14

75. Ibid.

76. I. Kant, 'On the Common Saying: This May be True in Theory, But It Does Not Apply in Practice', in H. Reiss (ed.), Political Writings, Engl. transl. by H.B. Nisbet (1970), at 74.

77. J. Feinberg, The Moral Limits of the Criminal Law, vol. 3, Harm to Self (1989), at 12

78. Ibid. 
son. ${ }^{79}$ This is the case, for instance, for people who are prone to the influence of distorting emotions. More generally, it is legitimate for the state to correct lack of information for those who chose not to gather it. An intervention may be autonomy-respecting when the target would consent to it if she were informed. Voluntariness can be a matter of degree. ${ }^{80}$ Given this account, questions arise as to whether soft paternalism is an independent liberty-limiting principle at all. ${ }^{81}$ Soft paternalism aims to protect a person from his/her nonvoluntary choices. For Feinberg, soft paternalism is not paternalism at all. ${ }^{82}$ Rather, it should be seen as consistent with liberalism. If it increases awareness, it increases freedom. Feinberg thinks that the definition of liberalism should be enlarged so that soft paternalism becomes a morally valid liberty-limiting principle.

Arguably, this is relevant to prejudice. What is at stake in prejudice is unconscious behaviour. If prejudice is likely to materialise in behaviour that causes serious harm, then it is possible to make a case in favour of state action in order to raise consciousness in the citizens about its existence. Once a person becomes aware of her prejudices and that those are unjustified, it is very likely that she will voluntarily modify her behaviour. Government intervention is respecting autonomy when it has the form of raising awareness. It is plausible that government is protecting the person from decisions and harm that is 'other' from himself or herself. There should be a threshold of harm that justifies a liberal government's interest in changing citizens' opinions for self-regarding acts, even when the suspicion exists that non-voluntary behaviour is at stake. This threshold should be defined in reference to the social harm that is caused, which means that the act is no longer selfregarding. The costs of retrieving or repairing harm weigh heavily upon society. The line between selfregarding and other regarding acts should be traced by defining what is remotely or trivially other-regarding. ${ }^{83}$ Triviality in this case is also defined in reference to the extent of the population that shares discriminatory prejudice. If it is shared by a good number of them, then it can certainly approach the threshold of serious harm. If more than fifty percent carry the prejudice, then social coexistence is seriously threatened. ${ }^{84}$

In the area of discriminatory prejudice, the distinction between self-regarding and other-regarding is fluid. Furthermore, the risk of direct harm to others also exists. Prejudice can materialise in discrimination in many areas of social life. Widespread prejudice can be destructive to the existence of society. As discussed earlier, soft paternalism can be justified in order to

79. J. Feinberg, 'Legal Paternalism', 16 Canadian Journal of Philosophy 105-124 (1971), J. Hanna, 'Hard and Soft Paternalism', in K. Grill and J. Hanna (eds.), The Routledge Handbook of the Philosophy of Paternalism (2018) 28-29.

80. Feinberg (1971), above n. 79, at 111

81. Feinberg (1989), above n. 77, at 12.

82. Ibid., at $14-16$.

83. Feinberg (1989), above n. 77, at 22.

84. This thought is inspired by Joel Feinberg's discussion of similar issues in Harm to Self, 23. ensure that behaviour prima facie self-regarding does not end up in behaviour that threatens social coexistence. The line between self-regarding and other regarding acts should be traced by defining what is trivially other-regarding. ${ }^{85}$ Triviality should be defined with reference to the extent of the population that shares the discriminatory prejudice. Widespread prejudice can affect social interaction and cooperation. Prejudice can encourage a feeling of malaise and stir animosity between social groups. It can lead to long judicial processes before courts. It can burden taxpayers with unnecessary costs to support this system. The social costs of repairing harm can become important. This means that preventive action can be encouraged in this case. If prejudice operates in unconscious ways, it is legitimate for the government to raise consciousness about what prejudice is and how it works. If, as analysed earlier, discriminatory behaviour is cognitive, it is legitimate for the state to engage in action that helps human beings realise how they form and modify their cognitive categories.

When concrete harm to the rights of others is at stake, then paternalism is not relevant. What is at stake is protecting others from harm. Soft paternalism makes sense only in order to change opinions towards preventing harm to others' rights. There is a wide spectrum of tools that are available to the state in order to handle cases of discrimination. Anti-discrimination law has emerged as an area of law because consciousness emerged that there are some behavioural patterns that introduce obstacles to social cohesion and social interaction. Human beings make decisions on the basis of some criteria like age, race, gender, sexual orientation, religion and disability, which affect others. They exclude them from having access to employment or to goods and services. Employment decisions on the basis of some of these criteria limit employment opportunities for part of the population. These decisions cause harm to the extent that they mean that these persons face additional obstacles in their lives in having what they need in order to survive. Providers of goods and services exclude persons from having access to them on the basis of the same criteria.

Any government intervention in this respect should be done with great caution and in a way that enhances the freedom of the citizens. Freedom of thought is a fundamental freedom. Government intervention in how citizens think and feel cannot be justified. It is also doubtful whether it can be effective. Eccentric and provocative beliefs should be tolerated out of respect for individual freedom. Locke's writings on toleration can be instructive in this area. ${ }^{86}$ He noted that government attempts to affect beliefs are vain. Human beings cannot conform their beliefs to the dictates of another. Beliefs are a mat-

85. Feinberg (1989), above n. 77, at 22.

86. See his 'Letter Concerning Toleration', in M. Goldie (ed.), A Letter Concerning Toleration and Other Writings (2010) and his 'Excerpts from a Third Letter for Toleration', in M. Goldie (ed.), A Letter Concerning Toleration and Other Writings (2010). 
ter of the 'inward and full persuasion of the mind' ${ }^{87}$ The care of each person's heart and mind belongs only to himself or herself. The power of civil authorities consists only in outward force. The nature of human understanding is such that it cannot be compelled to the belief of anything by outward force. Penalties are not effective in changing hearts and minds. Only persuasion can do so. 'Only Light and Evidence can work a change in Mens Opinions,' he notes (sic). ${ }^{88}$ Locke thinks that it should be everyone's moral duty to make use of arguments in order to persuade others to be virtuous. ${ }^{89}$ Government intervention should be accepted also in these terms, but only to the extent that it enhances the freedom of the citizens by raising awareness that allows them to make free, well-informed decisions. Locke also accepts that the magistrates, just like every other man in the state, may make use of arguments in order to 'teach, instruct and redress the Erroneous by Reason'. ${ }^{90}$ This is so because this respects the freedom of a person by maximising information that allows voluntary decision-making. Raising awareness about how prejudice operates should be done in a way that involves as little as possible the punitive mechanism of the state. Only persuasion is the legitimate means to change hearts and minds.

Locke also agrees that it may be legitimate for the state to enforce virtuous behaviour not because it is virtuous but because it ensures the preservation of society. ${ }^{91}$ And he notes that the good of the commonwealth is the standard of all human laws. Locke offers an interesting rationale for government intervention. It is legitimate for the state to enforce good behaviour, not because it is good in itself, but because not doing so might threaten the preservation of society. It is thus legitimate for the government to intervene because harmful behaviour threatens social interaction. If discriminatory prejudice causes substantial social harm, then it is legitimate for the state to intervene in order to eliminate it. If this harm is the result of social power dynamics, then it is legitimate for the state to engage in action towards affecting these dynamics. The state should engage in action that eliminates social power imbalances. From a liberal perspective, this does not mean that the state promotes a perfectionistic goal aiming to make citizens virtuous. Ideally, it should strive to create a situation where persons are not denied opportunities for characteristics that are projected upon them arbitrarily. Soft paternalism is legitimate to the extent that it addresses a person's reason and emotions towards eliminating prejudice. If prejudice is a preliminary judgment that invades consciousness and prevents a person from seeing things otherwise, it is legitimate for the state to do its best in order to raise awareness about its existence.

87. 'Letter Concerning Toleration', in M. Goldie (ed.), A Letter Concerning Toleration and Other Writings (2010) 39.

88. Ibid., at 40 .

89. Ibid.

90. Ibid.

91. 'Excerpts from a Third Letter for Toleration', in M. Goldie (ed.), A Letter Concerning Toleration and Other Writings (2010) 95.
There are some values that are fundamental to a wellordered society. The principle of equal respect for everyone is one of these values. Others include equal liberty, fair equality of opportunity and the social basis of mutual respect among citizens. Eliminating discriminatory prejudice serves as the social basis of mutual respect. Rawls's thought is very enlightening in this respect. He thinks that there are some ideas that can concentrate an overlapping consensus between comprehensive doctrines. ${ }^{92}$ Rawls has offered an interesting analysis of a test that a rule should pass in order to be accepted as a rule of a well-ordered society. ${ }^{93} \mathrm{He}$ discusses the idea of a well-ordered society as a society whose citizens all accept the same principles of justice, whose political and social institutions satisfy these principles, and whose citizens comply with these institutions considering them as just. $^{94}$ This publicly recognised conception of justice establishes a shared point of view from which citizens' claims on society can be adjudicated. ${ }^{95}$

In order to persuade for the validity of these rules Rawls engages in the thought experiment of the original position. He constructs the original position as a device offering an abstraction of the contingencies of each person in the social world. ${ }^{96}$ The social members under the veil of ignorance have a rational capacity, that is, they can have a conception first of their own good, and, second, a reasonable capacity, that is, they can have a capacity for a sense of justice, which means that they accept the validity of rules that regulate interaction. This thought experiment aims to enlighten norms of fair social cooperation. It is relevant in order to evaluate prejudice. It is a helpful thought experiment that can help us hypothesise what types of rules are just in the absence of factors that lead us towards making partial decisions. If we did not know the circumstances that define our existence, that is whether we have a characteristic that might lead others to discriminate against ourselves, then we would want society to establish the rules of fair social cooperation. We would want our society to be organised in a way that meets the needs of all participants. Under a veil of ignorance everyone would want not to experience discrimination. This provides legitimacy for the enforcement of anti-discrimination law.

For Rawls, these principles are political principles, not metaphysical - that is, they are principles that can be agreed upon independently of the comprehensive religious, philosophical and moral conceptions of each person. A society based on fair cooperation is thus based on the idea that there are some terms that each participant may reasonably accept in a reciprocal way with everybody else and that serve everybody's good. Rawls con-

92. J. Rawls, Political Liberalism (2005), at 39.

93. For an extended analysis, see I. Tourkochoriti, 'Revisiting HosannaTabor: The Road Not Taken', 49 Tulsa Law Review 45-96, at 88 (2013)

94. Rawls, above n. 92 , at 35

95. Ibid.

96. Ibid., at 16 
tinues with the idea that questions about constitutional essentials and matters of public justice are to be settled by appeal to political values alone, with respect to which political values have the weight to override all other values that may come into conflict with them. These political values cannot be overridden as they govern 'the basic framework of social life', which constitutes 'the very groundwork of our existence', and 'specify the fundamental terms of political and social cooperation'. Rawls argues that about these values there can be an overlapping consensus among reasonable comprehensive doctrines, even if these doctrines are in conflict. Or better, they can win the support of every citizen by addressing their reason, even if they adhere to conflicting comprehensive doctrines. Agreement is possible in circumstances of reasonable pluralism. Provided that all citizens are willing to use their public reason, they will agree on the fundamental role of some political values expressing the terms of fair social cooperation consistent with mutual respect of free and equal citizens. As Rawls notes, '[A]ny realistic idea of a well-ordered society may seem to imply that some such compromise is involved.'

Some of the ideas that people would agree upon in the original position are ideas that can concentrate an overlapping consensus even in our contemporary pluralistic societies. A well-ordered society is one that is governed by a political conception of justice that is the result of an overlapping consensus between opposing comprehensive doctrines and where unreasonable comprehensive doctrines do not gain enough currency to undermine society's essential justice. ${ }^{97}$ We can add to this reflection the unreasonable elements within comprehensive doctrines, such as elements that some human beings, e.g. homosexuals or persons with disabilities, should have unequal rights to live a meaningful life. To extend Rawls' thought further, it seems that there can be an overlapping consensus on the fact that everyone must have access to the goods and services that they need. A religious belief that expresses intolerance towards some social members should not be tolerated. If we did not know whether we are part of a social group that runs the risk of experiencing discrimination in the access to goods and services, we would want everyone to be spared from having to experience it.

These Rawls-inspired reflections can promote our thinking about the legitimacy of the state's efforts to raise awareness of discriminatory prejudice. It is legitimate to engage in soft paternalism towards changing hearts and minds in order to enable citizens to make decisions that respect the equal dignity of all social members. Under a veil of ignorance we would all want not to experience discrimination. In the same hypothetical situation, were we to exercise our public reason we would want vulnerable citizens to be protected by the state against civil society actors that discriminate against them. And it would be legitimate for the state to engage in preventive action in this respect. The previous analysis indicates that a version of soft paternalism in order to

97. Ibid., at 39 eliminate prejudice is permissible on a deontological and consequentialist basis. On a deontological basis it is legitimate for the government to attempt to change hearts and minds in order to protect human beings as ends in themselves. It is also justified on a consequentialist basis as in the long term it can have the best possible effects for individuals and societies.

\section{Legal Tools}

The previous section of this paper showed that there is a philosophical justification behind recognizing positive obligations for the state to engage in action that aims to eliminate prejudice. Many international conventions which establish these positive obligations reflect this philosophical justification. ${ }^{98}$ Nudging and soft paternalism need to go together with the enforcement of legal rules forbidding discrimination in some instances. In cases where a discriminatory decision cannot be prevented, it is very important to use the law in order to reverse its effects when harm to others exists. Law has an expressive function too. ${ }^{99}$ Legislation against discrimination in the access to employment and to goods and services sends a message. Discrimination on the forbidden grounds is wrongful. The analysis of types of harm previously in this article shows that it can be both material and immaterial. When it is immaterial it is difficult to justify government intervention for liberals. Civil responsibility is, in any case, highly preferable to criminal responsibility.

In the enforcement of anti-discrimination law Durkheim's insights are very relevant. Durkheim noted that the predominance of criminal sanctions is characteristic of societies of mechanical solidarity. ${ }^{100}$ Those societies are not characterised by an advanced division of labour, and thus a sense of complementarity among social members that transforms the moral consciousness of each individual has not emerged yet. Societies characterised by mechanical solidarity need to ensure the allegiance of their members by enforcing the respect of some deeply held values. Hence, the predominance of criminal sanctions in their midst. For Durkheim, societies with sophisticated division of labour have succeeded in creating a moral consciousness of complementarity. This sense of complementarity holds their members together. This means that social members do not need a strong punitive mechanism to guarantee allegiance to the community. When a member violates a rule, society needs to restore the situation to the status quo ante. It needs to turn back the clock to the situation that existed

98. For an analysis of these international legal tools see Stephanie E. Berry, "A Positive State Obligation to Counter Dehumanisation under International Human Rights Law", in this issue.

99. See C.R. Sunstein, 'On the Expressive Function of Law', 144 University of Pennsylvania Law Review 2021 (1996), R. Mullender, 'Racial Harassment, Sexual Harassment and the Expressive Function of Law', 61 Modern Law Review 236 (1998).

100. D. Émile, The Division of Labor in Society, transl by L.A. Coser. (1984 [1893]). 
before the violation of the rule. Therefore, in the area of enforcing anti-discrimination law it is important to focus on legal sanctions that strengthen this sense of complementarity and allegiance to the community. Civil sanctions can achieve this goal better than criminal sanctions. Criminal sanctions are a sign of harshness. They are a sign of insecurity of a community. A community punishes harshly because it feels threatened. Civil sanctions are a sign that the community is merely restoring the situation to the status quo ante and is willing to move on.

In the area of employment discrimination, mechanisms and solutions that reflect a conciliatory attitude are also legitimate. Finding solutions that involve reasonable accommodation is also necessary. The concept of reasonable accommodation does not imply that the rights of one party win over those of the other. On the contrary, it points towards a spirit of finding a workable solution that respects the rights of both employers and employees. Finding a reasonable accommodation is very relevant in the area of religious freedom and dress codes and in the area of disability and age discrimination. Enforcing anti-discrimination legislation in the access to employment is fundamental towards eliminating discrimination and changing attitudes and hearts and minds. If human beings have a natural tendency to prefer their same and to project negative stereotypes onto those that are different from them, then it is important to attempt to eliminate this attitude. Offering employment opportunities to persons beyond stereotypes can allow them to show who they truly are.

Another legal tool that can help in this direction is enforcing anti-discrimination legislation in the access to goods and services. A debate has emerged related to the possibility of some citizens to put forward religious objections in the application of legislation that outlaws discrimination in the access to goods and services. The debates relate to whether anti-discrimination law in the access to goods should be enforced, for instance, upon providers of cakes for the celebration of same sex marriages. ${ }^{101}$ Locke's objections emerge in this case anew. Should persons be forced to fulfil a legal obligation if their religious convictions dictate otherwise? If the point of having anti-discrimination law is to bring about a change in attitudes then it should be enforced even upon objections of this kind. Civil Rights legislation in the US eliminated race discrimination in the access to goods and services because it obliged providers not to discriminate on the basis of race. ${ }^{102}$ As our societies evolve, we become more aware of different ways of exercising social power and thus of discriminating. We real-

101. The debate relates to the recent rulings Masterpiece Cakeshop Ltd v. Colorado Civil Rights Commission in the US and138 S. Ct. 1719, 584 US _, 201 L. Ed. 2d 35 and Lee v. Ashers Baking Company Ltd [2018 UK SC 49] in the UK. The case in the UK did not concern a wedding per se but the preparation of a cake expressing a message in favour of same-sex marriage to be brought to a political event in favour of recognising same-sex marriage.

102. For a relevant discussion see also Anita Böcker, Can Non-discrimination Law Change Hearts and Minds?, in this issue, 3.2. ised relatively recently that we need to eliminate discrimination on the basis of sexual orientation. The rights of homosexual persons are gaining recognition, while the rights of transgender persons are not recognised to the same extent yet. It is very important for legislation to take into consideration the need to protect the rights of these new groups. Just like the government in the US in the past had to enforce legislation against racial discrimination in the access to goods and services, it should now enforce it in order to protect other social groups. Being part of a society means accepting the enforcement of rules that operate in a way that eliminates prejudice. In this case harm is more tangible. As analysed earlier, it is both material and immaterial. The social risk that the person with the protected characteristic might not be able to obtain the goods and services that she needs from another provider is too heavy to take. There may be an undue burden upon the person asking for the good in this case. A well-ordered society needs to ensure that human beings have the goods that they need in order to survive.

Depending on context, the enforcement of anti-discrimination law upon claims for religious exemptions can take many forms. In South Africa, the High Court has held that a church that refuses to 'solemnise' same-sex marriage 'inherently diminishes the dignity' of persons in same-sex relationships. ${ }^{103}$ A similar ruling would be unthinkable in the US, where the doctrine of ministerial exception under the First Amendment precludes government intervention in religious matters. The principle of equality in the South African Constitution entirely redefines the hierarchy of constitutional values. It leads jurists to interpret the constitution as attributing secondary importance to freedom of religion. In legal systems that give priority to freedom of religion, such as that of the US, a similar ruling would be unthinkable. In these cases the appropriate criterion for tracing the line between freedom of religion and anti-discrimination law can be found in the degree of involvement in the samesex marriage ceremony. A church cannot be obliged to 'solemnise' a same-sex marriage. This would imply deep involvement in the internal workings of the church. A bakery that provides a cake should be asked to do so. A conscientious objection should not be recognised here. Such an objection should only be recognised to providers of services that are deeply involved in the ceremony, such as oath writers.

Furthermore, scholars have made a number of suggestions to address discriminatory behaviour based on stereotype. If prejudice operates unconsciously, scholars have argued that the non-discrimination principle must evolve to encompass a prescriptive duty of care to identify and control for category-based judgment errors and other forms of cognitive bias in intergroup settings. ${ }^{104}$ In the US, the Supreme Court has held that a plaintiff can shift the burden of proof to the defendant by showing simply that her group status 'played a role' in the

103. Gaum v. Van Rensburg, NO 2019 2All SA 722 (GP).

104. Krieger, above n. 7. 
decision or action taken against her. ${ }^{105}$ The plaintiff would not have to prove that it was the sole reason, nor would she have to establish that the reasons proffered by the defendant were 'cover-ups' for a real discriminatory reason. ${ }^{106}$ Commentators note that, unfortunately, courts have not been very successful in their efforts to define the respective spheres of application of the pretext and mixed-motives theories of liability. ${ }^{107}$ Courts determine whether pretext or mixed-motives theory will apply to a given case based on the type of evidence a plaintiff proffers. Courts also disagree on the meaning of 'direct evidence' or 'evidence directly tied to discrimination'. For these reasons Linda Hamilton Krieger suggests that the pretext model of individual disparate treatment proof should be replaced with a unitary motivating factor analysis. ${ }^{108}$

Other scholars are in favour of a 'negligence' approach to employment discrimination. ${ }^{109}$ Negligence is a theory according to which there is breach of duty recognised by law for the protection of others. This duty exists either in the common law, in legislation or administrative regulation. Anti-discrimination law creates an obligation for employers to treat employees without regard to race, colour, religion, sexual orientation, disability, age or national origin. According to this view, employers who violate this obligation even without intending harm, since prejudice is unconscious, should incur responsibility. When there is a duty to provide a reasonable accommodation, negligent discrimination exists when the employer does not discharge this duty properly.

A doctrine of strict liability has led to the emergence of the theory of disparate impact. According to this theory, there is discrimination even in the absence of intent to discriminate when a neutral policy has a disproportionate effect upon a social group. ${ }^{110}$ The concept evolved to include cases of 'systemic discrimination', where courts are looking into whether broader social patterns have discriminatory effects upon social groups. It migrated in Europe with the term 'indirect discrimination'. ${ }^{111}$ Courts should be encouraged to think in these terms in order to make wider policy suggestions towards eliminating discrimination. Courts in the US and in Europe have already elaborated a doctrine of indirect discrimination. There is more that they can and should do in this area in the future.

All these legal tools can attack prejudice directly or indirectly. They exercise a pedagogical function and encourage employers to become conscious of how prejudice works. Increasing consciousness can lead to modifying behaviours. In the cases of unconscious discrimination the legal sanctions should not be compensatory

\footnotetext{
105. Price Waterhouse v. Hopkins, 490 U.S. 228 (1989) 244.

106. Ibid., at 246

107. Krieger, above n. 7 , at 1220

108. Ibid., at 1241.

109. D.B. Oppenheimer, 'Negligent Discrimination', 141 University of Pennsylvania Law Review 899, at 915-17 (1993).

110. Griggs v. Duke Power Co., 401 U.S. 424 (1971).

111. See I. Tourkochoriti, 'Jenkins v. Kingsgate and the Migration of the U.S. Disparate Impact Doctrine in EU Law', in F. Nicola and B. Davies (eds.), EU Law Stories (2017).
}

or punitive damages. Since cognitive biases are to a great extent unintentional, heavy sanctions do not appear just. Neither do they guarantee a change in attitudes. On the contrary, they may heighten intergroup animosity. The state has a more important role to play in eliminating prejudice through pedagogical methods.

\section{Conclusion}

As I argued in this article, it is legitimate for the state to practice soft paternalism towards changing hearts and minds in order to prevent behaviour that is discriminatory. Liberals accept that it is not legitimate for the state to intervene in order to change how people think because ideas and beliefs are wrong in themselves. It is legitimate for the state to intervene with the actions of a person only when there is a risk of harm to others and when there is a threat to social coexistence. Furthermore, it is legitimate for the government to try to persuade citizens to eliminate their prejudice because it can lead them to discriminatory behaviour that can threaten social coexistence. In the area of preventing discrimination a more sophisticated reasoning is required as harm to others is material but also immaterial. Preventive action of the state is legitimate if we consider the serious harm that discrimination causes. Discrimination causes material and immaterial harm. It reinforces a broader context of social power. It harms the social standing of the person. It causes both psychological and existential harm. All these harms threaten peaceful social coexistence. Thus, it is legitimate for the state to raise awareness of what prejudice is and how it works. As Locke insightfully notes, although sanctions cannot change beliefs, persuasion can. In fact, Locke discusses a moral duty to try to change beliefs that threaten social coexistence. As Rawls encourages us to think, under a veil of ignorance of whether we have a characteristic that might lead to discrimination against us, we would all opt for rules of justice that eliminate discrimination. Changing hearts and minds can be justified as a matter of principle. It can also be justified for consequentialist considerations. Research in the areas of behavioural psychology, neuroscience and social psychology indicates that it is possible to bring about a change in hearts and minds. Encouraging a person to adopt the perspective of the person who has experienced discrimination can lead to understanding her situation. This can lead a person to critically evaluate her prejudice.

When discrimination materialises in action, it is legitimate to enforce anti-discrimination law. Enforcing antidiscrimination law should be done with caution as it can also threaten social bonds. The state has a broad array of tools that it can use in this area. It can first 'nudge' the citizens towards behaviour that is not discriminatory. Nudging is not objectionable in this area to the extent that it aims to incite towards behaviour that is not discriminatory. Through civic education the state can encourage empathetic understanding towards persons 
that are members of minority groups. If the wrongs of discrimination are many and the harms particularly acute upon the social members it concerns, then it is legitimate for the state to deploy a vast array of mediums towards eliminating it. It can assist NGOs with valuable expertise towards engaging in campaigns that raise awareness against prejudice. And it can enforce antidiscrimination law in the access to employment and to goods and services. The state should also be conscious to encourage solidarity among social groups. Its pedagogical and ideological mechanisms should be oriented towards enhancing feelings of complementarity. 